\title{
Interprofessional Education in U.S. and Canadian Dental Schools: An ADEA Team Study Group Report
}

\author{
Allan J. Formicola, D.D.S., M.S.; Sandra C. Andrieu, Ph.D.; Judith A. Buchanan, Ph.D., \\ D.M.D.; Gail Schneider Childs, R.D.H., M.P.H.; Micaela Gibbs, D.D.S.; \\ Marita R. Inglehart, Dr. phil. habil.; Elsbeth Kalenderian, D.D.S., M.P.H.; \\ Marsha A. Pyle, D.D.S., M.Ed.; Kim D'Abreu, M.P.H.; Lauren Evans
}

Abstract: The state of interprofessional education (IPE) in U.S. and Canadian dental schools was studied by the American Dental Education Association (ADEA) Team Study Group on Interprofessional Education. The study group reviewed the pertinent IPE literature, examined IPE competencies for dental students, surveyed U.S. and Canadian dental schools to determine the current and planned status of IPE activities, and identified best practices. Members of the study group prepared case studies of the exemplary IPE programs of six dental schools, based on information provided by those schools; representatives from each school then reviewed and approved its case study. Six reviewers critiqued a draft of the study group's report, and study group members and reviewers met together to prepare recommendations for schools. This report identifies four domains of competence for student achievement in IPE and summarizes responses to the survey (which had an 86 percent response rate). It also includes the case descriptions of six schools' IPE programs and the study group's recommendations for dental schools. The report concludes that there is general recognition of the goals of IPE across U.S. and Canadian dental schools, but a wide range of progress in IPE on the various campuses. Challenges to the further development of IPE are discussed.

Dr. Formicola is Dean Emeritus, College of Dental Medicine, Columbia University; Dr. Andrieu is Associate Dean for Academic Affairs, School of Dentistry, Louisiana State University; Dr. Buchanan is Interim Dean, School of Dentistry, University of Minnesota; Ms. Childs is Associate in Dentistry, College of Dentistry, University of Florida; Dr. Gibbs is Clinical Assistant Professor, College of Dentistry, University of Florida; Dr. Inglehart is Associate Professor, School of Dentistry, University of Michigan; Dr. Kalenderian is Assistant Professor and Chair of Oral Health Policy and Epidemiology, Harvard School of Dental Medicine; Dr. Pyle is Dean, School of Dentistry, University of Missouri-Kansas City; Ms. D’Abreu is Senior Vice President for Access, Diversity, and Inclusion, Policy Center, American Dental Education Association; and Ms. Evans is Program Manager, Policy Center: Access, Diversity, and Inclusion, American Dental Education Association. Dr. Formicola was Chairman of the ADEA Team Study Group on Interprofessional Education; Dr. Andrieu, Dr. Buchanan, Ms. Childs, Dr. Gibbs, Dr. Inglehart, Dr. Kalenderian, and Dr. Pyle were members of the study group; and Ms. D’Abreu and Ms. Evans were ADEA staff members on the study group. Direct correspondence and requests for reprints to Dr. Allan J. Formicola, Columbia University, College of Dental Medicine, 630 West 168 ${ }^{\text {th }}$ Street, Box 100, New York, NY 10023; 973-377-4977; ajf3@columbia.edu.

Keywords: dental schools, dental education, interprofessional education, intraprofessional education, academic health centers

$\mathrm{T}$ Trends in health professions education are often influenced by reports that analyze national health care workforce needs, practice patterns of the various professions, and data on the quality of care provided, the cost-effectiveness of care, and the access to care. Over the past decade, the health professions have been urged to improve collaboration among their practitioners with the objective of improving the quality of care they provide, especially the complex care needed for an aging population and patients with chronic diseases.

A body of knowledge has developed in the literature concerning what is now referred to as interprofessional education (IPE) and practice- $-\mathrm{a}$ term used to describe the recent movement to break down professional barriers that can inhibit the easy flow of prevention and management of disease for individual patients and population groups. Academic health center schools as well as other health professions programs are being encouraged to introduce joint learning experiences into their educational programs, so that students will graduate with a keener understanding of the roles and responsibilities of related health professions and how collaboration can lead to better care.

There are many challenges to developing and implementing IPE, from crowded curricula to scheduling difficulties and from lukewarm support of leader- 
ship to a paucity of evaluation of emerging coursework and clinical care outcomes. In spite of these barriers, a number of academic health centers are progressing towards planning and implementing interprofessional experiences for their students. The Interprofessional Education Collaborative Expert Panel, ${ }^{1}$ a group comprised of leaders from six health professions' national organizations, has identified four IPE core competency domains that all health professions should include in their curricula. The four are values/ethics, roles/ responsibilities, interprofessional communication, and teams and teamwork. Consequently, accrediting agencies are adding standards requiring schools to structure IPE activities for their students.

The American Dental Education Association (ADEA) Team Study Group on Interprofessional Education was formed after the 2011 ADEA Annual Session \& Exhibition, which had IPE as its theme. Members of the study group reviewed the literature, surveyed dental schools in the United States and Canada, wrote case studies that described best practices, and developed recommendations for dental schools regarding IPE competencies and curriculum content. The purpose of this report is to share the findings and recommendations of the study group, with the particular purpose of assisting academic dental institutions in the United States and Canada as they undergo curriculum evaluation and revision and prepare for the accreditation self-study process.

\section{Recent Thinking on IPE}

The term "IPE" refers to occasions when students from two or more health professions learn together during all or part of their professional training with the objective of cultivating collaborative practice to improve the quality of patient care at the individual and population level. This definition is adapted from that used by the Centre for the Advancement of Interprofessional Education (www.caipe.org. uk/resources/defining-ipe/).

A World Health Organization (WHO) Study Group on Interprofessional Education and Collaborative Practice conducted a review of the literature between 1988 and 2009 and determined learning outcomes or competencies expected from IPE. ${ }^{2}$ The six outcomes/themes were teamwork, roles/ responsibilities, communication, learning/reflection, the patient, and ethics/attitudes, and each theme had several subthemes. For example, negotiation and conflict resolution was included as a subtheme under

Background on the ADEA Team Study Group on Interprofessional Education

Finding the correct balance among competing priorities in the curricula of health professions programs is difficult, given the explosion of scientific and technological advances. Faculty members face constant challenges to maintain a contemporary curriculum, especially in emerging areas. The ADEA Commission on Change and Innovation in Dental Education (ADEA CCI) (www.adea.org/adeacci/Pages/default.aspx) and the ADEA Curriculum Resource Center (ADEA CRC) (www.adea.org/crc/Pages/default.aspx) have many resources to help dental faculty members meet the challenges of continually improving their curricula. Beginning in 2006, the Macy project on New Models of Dental Education (with funding from the Josiah Macy Jr. Foundation and the National Institute of Dental and Craniofacial Research) brought together experts in content areas to produce a series of three reports aimed at assisting faculty in the process of updating their curricula. These reports, entitled New Opportunities for Dentistry in Diagnosis and Primary Health Care, Genetics and Its Implications for Clinical Practice and Education, and Curriculum and Clinical Training in Oral Health for Physicians and Dentists, are available at www.adea.org/publications/Pages/NewModelsofDentalEducation.aspx.

Adopting a similar organization as the Macy study, the ADEA Team Study Group on Interprofessional Education was formed to consider competencies needed for graduates of academic dental institutions that address interprofessional education (IPE), the theme of the 2011 ADEA Annual Session \& Exhibition. Specifically, the study group had the following goals, to:

1. determine the competencies students need to develop to become members of interprofessional teams;

2. conduct a survey to assess the current state of interprofessional and intraprofessional education in dental schools in the United States and Canada;

3. describe the best practices of schools with exemplary programs; and

4. develop recommendations to assist dental schools with assessing and enhancing their efforts related to providing interprofessional and intraprofessional education.

The study group developed a draft document on suggested competencies for dental students, surveyed the U.S. and Canadian dental schools about their current and planned curricular efforts in IPE, wrote case studies incorporating the best practices in six of the surveyed schools, and developed recommendations for schools as they plan and develop IPE course content and modes of instruction. The study group's report was reviewed during a meeting at the 2012 ADEA Annual Session \& Exhibition and then finalized for distribution to all dental schools. 
communication. The WHO study group emphasized that this review of the literature created a comprehensive list of learning objectives and a starting point for defining outcomes to be achieved through IPE.

In their report, Parsell and Bligh ${ }^{3}$ described how seven disciplines went about creating a multidisciplinary education program. These authors identified six principles to guide the development of such programs: 1) detailed planning and organization involving all stakeholders, 2) integration of theory with practice, 3 ) interactive student-centered learning activities, 4) teachers as role models, 5) a comfortable learning environment, and 6) evaluation for research and further development.

There has been a paucity of studies in the past that rigorously evaluated the outcomes of IPE on a study population, but some have recently been published. A systematic review of the literature found six studies that analyzed the outcomes of a program designed around a mixed group of medical practitioners (physicians, nurses, and medical assistants). ${ }^{4}$ In that review, two studies found that the IPE intervention had no effect, two reported a significantly higher positive outcome, and two had a mixed outcome. Cameron et al. reported on a wellplanned experimental IPE session with first-year students from nine disciplines (dentistry, medical radiation sciences, medicine, nursing, occupational therapy, pharmacy, physical therapy, speech language pathology, and social work). ${ }^{5}$ Pre- and post-session questionnaires completed by 399 matched pairs of health science students showed a significant positive change in students' attitudes and perceptions from before to after a 2.5-hour IPE session. Promoting teamwork, team-building, understanding the roles of the various professions, and increasing trust in the judgment of others all improved from the baseline to the post-session assessment.

These studies used a variety of methods to evaluate or guide IPE. Parsell and Bligh developed a Readiness for Interprofessional Learning Scale (RIPLS) that incorporates two learning scales. ${ }^{3}$ The first scale, Teamwork and Collaboration, measures students' belief that shared learning is beneficial; the second scale, Professional Identity, focuses on assessing role and professional identity. The results of the eighteen-item questionnaire can be used by facilitators to discuss with students how they think and feel about themselves and how they think about others in an interprofessional setting. Cameron et al. used two instruments to measure change in student attitudes and perceptions about IPE. ${ }^{5}$ The Interprofes- sional Attitudes Questionnaire ${ }^{6,7}$ consists of fourteen statements about how students feel about IPE, while the Interdisciplinary Education Perception $\mathrm{Scale}^{8}$ has eighteen statements related to how students perceive their profession. In these studies, the scales were administered two weeks prior to the IPE session and again afterwards. These questionnaires were followed up with a focus group to explore, in greater depth, perceptions and challenges identified by the students. Another approach to assessing the IPE learning experience is to use an objective structured clinical examination (OSCE). Faculty members from ten health science disciplines used a modified Delphi process to generate the content for the OSCE. The Delphi process generated ten themes and clinical scenarios for incorporation into the OSCE, including complex chronic disease management, elderly care, ethics, and diabetes. ${ }^{9}$

In a review of the literature prior to 2006 , Rafter et al. found minimal involvement of dental students in IPE. ${ }^{10}$ These authors also surveyed a convenience sample of leaders at seven academic health centers in the United States. The data showed that IPE was not a high priority and not likely to be integrated into already crowded curricula. The interviews showed that these respondents were comfortable with the "silo" approach and viewed this fact and poor communication among professions as reasons thwarting the development of IPE. These leaders of academic health centers, however, generally agreed about subject areas for IPE and mentioned such topics as ethics and professionalism, skills to conduct evidence-based practice, communication skills training, behavioral science programs, teamwork, and leadership.

\section{IPE in Dental Education}

While health professions schools may wish to develop their own rationales on which to base interprofessional student experiences, the following four considerations are reasons why the study group believes dental education should engage in such an endeavor:

1. Dentistry is a critical component of the primary care system in the United States, and its practitioners must be able to communicate effectively with other primary care providers.

2. Management of chronic health conditions, such as diabetes, has consequences for patients' oral health and is affected by their oral health. Such 
patients require coordination of care between dentistry and the other health professions.

3. Efficient and quality oral health care for both prevention and treatment of oral disease can best be achieved when members of the oral health care team work together collaboratively as well as with members of other health professions.

4. Dentistry is expected to interact with community public health systems to improve access to care and implement community-wide preventive measures.

A vivid example of the first item is dentistry's growing relationship with the American Association of Pediatrics (AAP). This organization now has extensive information on oral health and the role of the pediatrician in caring for pediatric patients' oral health care needs on its website, including this statement: "Together we can make a difference by improving communication and collaboration between the medical and dental homes and making pediatricians and other health professionals an essential part of the oral health team!" (www2.aap.org/commpeds/ dochs/oralhealth/). The need for interprofessional training while future child health care providers are in school was widely recognized following a 2006 study that reported pediatricians' and family physicians' role in the oral health context is important but that these providers lack oral health-related knowledge and training, which prevents them from being more actively involved in the management of early childhood caries. ${ }^{11}$

As background for a study of IPE in dental education, the ADEA Team Study Group on Interprofessional Education reviewed two documents: Core Competencies for Interprofessional Collaborative Practice, ${ }^{1}$ developed by the Interprofessional Education Collaborative Expert Panel, which included ADEA representatives; and Team-Based Competencies: Building a Shared Foundation for Education and Clinical Practice, ${ }^{12}$ the proceedings of a conference on that topic. Much consideration, review, and expertise grounded the competencies proposed in these two works, which were developed from the foundation provided in three Institute of Medicine reports. ${ }^{13-15}$ The recommended competency domains along with a selection of the associated general competency statements identified by the Interprofessional Education Collaborative (IPEC) and supported by the Macy report were adopted by our study group as the basis for our efforts. These domains/general competency statements are as follows:
- Competency Domain 1: Values/Ethics for Interprofessional Practice

General Competency Statement: Work with individuals of other professions to maintain a climate of mutual respect and shared values.

- Competency Domain 2: Roles/Responsibilities General Competency Statement: Use the knowledge of one's own role and those of other professions to appropriately assess and address the health care needs of the patients and populations served.

- Competency Domain 3: Interprofessional Communication

General Competency Statement: Communicate with patients, families, communities, and other health professionals in a responsive and responsible manner that supports a team approach to the maintenance of health and the treatment of disease.

- Competency Domain 4: Teams and Teamwork

General Competency Statement: Apply relationship-building values and the principles of team dynamics to perform effectively in different team roles to plan and deliver patient/population-centered care that is safe, timely, efficient, effective, and equitable.

Table 1 summarizes these competency domains and general competencies, offers assessment measures recommended by the study group, and crossreferences these competencies with those reported by the IPEC. The table also includes the revised Commission on Dental Accreditation (CODA) standards regarding interprofessional education and teamwork.

\section{Survey of U.S. and Canadian Dental Schools}

In addition to its review of relevant research, the study group conducted a survey to collect information from the academic deans of U.S. and Canadian dental schools concerning their current educational activities related to IPE, including any best practices they were willing to share; their schools' activities related to the revised CODA standards related to IPE; and the way their schools address IPE-related competencies. A recruitment e-mail with a web link to the survey was sent to the academic deans on December 9, 2011, and the website was closed on January 20, 2012. A first follow-up e-mail was sent on December 27, 2011, and a second follow-up e-mail on January 5, 2012. By January 10, 2012, thirty-six of the sixty-two U.S. dental schools and four of the 


\begin{tabular}{|c|c|c|c|}
\hline $\begin{array}{l}\text { Competency } \\
\text { Domain }\end{array}$ & Competencies & Means of Assessment & $\begin{array}{l}\text { Cross-Reference } \\
\text { to IPEC } \\
\text { Competencies }\end{array}$ \\
\hline \multirow[t]{4}{*}{ Values/Ethics } & $\begin{array}{l}\text { Work with individuals of other professions to maintain a climate } \\
\text { of mutual respect and shared values. }\end{array}$ & & VE \\
\hline & $\begin{array}{l}\text { 1. Demonstrate high standards of ethical conduct and quality of } \\
\text { care in one's contributions to team-based care. }\end{array}$ & $\begin{array}{l}\text { Develop norms and standards as a team. } \\
\text { Measure adherence to norms and standards through } 360^{\circ} \text { evalu- } \\
\text { ations. }\end{array}$ & VE7 \\
\hline & $\begin{array}{l}\text { 2. Demonstrate sensitivity to and understanding of the diversity } \\
\text { and cultural awareness of the roles of other health professions, the } \\
\text { diversity of patients, and health care systems in order to provide } \\
\text { competent patient-centered care. }\end{array}$ & $\begin{array}{l}\text { Development of concrete patient-centered approaches and ques- } \\
\text { tions to address care delivery in a culturally competent manner. }\end{array}$ & VE3 \\
\hline & $\begin{array}{l}\text { 3. Manage ethical dilemmas specific to interprofessional patient/ } \\
\text { population-centered care situations. }\end{array}$ & IPE group case studies outcome & VE8 \\
\hline \multirow[t]{5}{*}{$\begin{array}{l}\text { Roles and Re- } \\
\text { sponsibilities }\end{array}$} & $\begin{array}{l}\text { Use the knowledge of one's own role and those of other profes- } \\
\text { sions to appropriately assess and address the health care needs of } \\
\text { the patients and populations served. }\end{array}$ & & $\mathrm{RR}$ \\
\hline & $\begin{array}{l}\text { 1. Demonstrate skills in working with a variety of health care } \\
\text { providers to optimize patient care and learning. }\end{array}$ & $\begin{array}{l}\text { Implement a standardized feedback mechanism. } \\
\text { TeamSTEPPS } \\
\text { RIPLS } \\
\text { IPE Perception Scale }\end{array}$ & \\
\hline & $\begin{array}{l}\text { 2. Demonstrate self-assessment skills and know the limitations of } \\
\text { one's own skills. }\end{array}$ & Self-assess one's role response in IPE team clinical setting. & \\
\hline & $\begin{array}{l}\text { 3. Demonstrate continual learning about one's roles and those of } \\
\text { others in a variety of health care teams. }\end{array}$ & $\begin{array}{l}\text { Evaluate through } 360^{\circ} \text { evaluations. } \\
\text { TeamSTEPPS } \\
\text { RIPLS } \\
\text { IPE Perception Scale (pre- and post-assessment) }\end{array}$ & \\
\hline & $\begin{array}{l}\text { 4. Develop care teams that use the full scope of unique and } \\
\text { complementary skills, abilities, and knowledge of all team mem- } \\
\text { bers available to optimize care. }\end{array}$ & $\begin{array}{l}\text { Evaluate team role-process after clinical experience. } \\
\text { TeamSTEPPS } \\
\text { RIPLS } \\
\text { IPE Perception Scale (pre- and post-assessment) }\end{array}$ & \\
\hline \multirow[t]{2}{*}{ Communication } & $\begin{array}{l}\text { Communicate with patients, families, communities, and other } \\
\text { health professionals in a responsive and responsible manner that } \\
\text { supports a team approach to the maintenance and promotion of } \\
\text { health and treatment of disease. }\end{array}$ & & $\mathrm{CC}$ \\
\hline & $\begin{array}{l}\text { 1. Demonstrate effective skills in listening and communicating } \\
\text { with patients, families, peers and communities: } \\
\text { a. use effective communication tools/techniques and master new } \\
\text { communication tools/techniques, including the use of informatics; }\end{array}$ & $\begin{array}{l}\text { Standardized patient communication evaluation. } \\
\text { Role-play difficult conversations with peers or standardized } \\
\text { patients. }\end{array}$ & $\begin{array}{l}\text { CC1 } \\
\text { CC4 } \\
\text { CC6 }\end{array}$ \\
\hline
\end{tabular}


2. Provide constructive feedback to team members in a respectful manner, while accepting feedback from others to improve team effectiveness.

3. Recognize how one's own uniqueness, including experience level, expertise, culture, power, and hierarchy within the health care team, contributes to effective communication, conflict resolution, and positive interprofessional working relationships.

Team/Teamwork Apply relationship-building values and the principles of team dynamics to perform effectively in different team roles to plan and deliver patient- and population-centered care that is safe, timely, efficient, effective, and equitable.

1. Demonstrate appropriate reflective skills to evaluate self and team roles and responsibilities in group activities.

2. Evaluate effective team processes and outcomes to optimize patient care and ensure quality improvement.

3. Assess team performance and progress on a continuous basi relative to attainment of goals, and self-correct using process improvement strategies.

4. Understand the stages of team development, and actively work toward becoming a high-performance team.
Complete and discuss group process evaluation form; respond to

CC5

evaluation by other team members.

Implement $360^{\circ}$ evaluations of team.

TeamSTEPPS

Reflective writing exercise evaluation

TeamSTEPPS

RIPLS

IPE Perception Scale (pre- and post-assessment)

Reflective writing exercise, possibly over time

Engage in daily or weekly journaling.

TeamSTEPPS

RIPLS

IPE Perception Scale (pre- and post-assessment)

Evaluate process/patient care satisfaction or outcome during standardized patient team exercise.

Implement quality improvement measures.

TeamSTEPPS

TT9

Reflective writing exercise after team clinical experience

Use PDSA techniques to continuously measure and improve

processes.

TeamSTEPPS

RIPLS

IPE Perception Scale (pre- and post-assessment)

Conduct writing exercise about team process.

Set measurable goals.

Assign roles and responsibilities according to skills and interests.

Measure outcomes continuously.

Develop and adhere to time frames.

TeamSTEPPS

RIPLS

IPE Perception Scale (pre- and post-assessment) 
ten Canadian dental schools had responded. At this time, individual e-mails and follow-up phone calls from the first author encouraged additional schools to respond by the time the website was closed. As a result, a total of fifty-five of the sixty-two U.S. dental schools and four of the ten Canadian dental schools participated in the survey. An additional three schools responded anonymously, bringing the total number of responses to sixty-two out of seventy-two contacted schools, for an overall response rate of 86 percent.

\section{Current IPE Activities}

The recruitment e-mail informed the recipients that this survey was designed to assess their schools' current and future curricular activities concerning IPE. The first question asked which other health professions programs they have on their campus and with which of these programs they collaborate. Thirty-nine of the fifty-one dental schools with a medical school on campus reported collaborating with it (Table 2). The second most frequently reported collaboration was with dental hygiene programs. All of the thirty-one dental schools with a dental hygiene program on campus reported that they collaborate with this program. In addition, five schools reported collaborating with a dental hygiene program located off campus. The third most frequently named collaborative program was nursing, with twenty-nine schools reporting IPE interactions with nursing schools.
Twenty-one schools reported having health professions programs on campus that were not on the list of programs in the survey. The most frequently mentioned programs were occupational therapy $(\mathrm{N}=7)$, optometry $(\mathrm{N}=6)$, public health $(\mathrm{N}=5)$, and nutrition $(\mathrm{N}=4)$; also mentioned were audiology, business, education, engineering/bioengineering, health/health informatics, journalism, kinesiology, podiatry, recreation therapy, respiratory therapy, speech and language pathology, and veterinary medicine. Fourteen schools reported that they also collaborate with schools and programs off campus such as dental hygiene and dental assisting, medicine, nursing, and pharmacy.

Development of some questions on the survey was aided by a presentation at the 2011 ADEA Fall Meetings in San Antonio in which several academic deans described their IPE activities. A list of activities was created for the survey based on these presentations in order to inquire, more broadly, what was being done in the schools and which other health professions programs were part of collaborative activities. The most common joint activities were reported on the survey to be volunteer activities (66 percent of respondents), followed by clinical activities (60 percent), service-learning projects (52 percent), basic science courses (32 percent), and communication training (31 percent) (Table 3). Thirteen schools named additional joint activities beyond those in the provided list: these included an interdisciplinary team training sponsored by a geriatric education center;

\section{Table 1. Interprofessional education (IPE) competency domains, competencies, and examples of means of assessment}

(continued)

Sources:

Column 1: Competency domains from Interprofessional Education Collaborative (IPEC) Expert Panel. Core competencies for interprofessional collaborative practice (www.aacn.nche.edu/education-resources/IPECReport.pdf).

Column 2: Competencies suggested by the ADEA Team Study Group.

Column 3: Means of assessment selected from the literature and recommended by the ADEA Team Study Group. For the IPE perception scale, see www.ncbi.nlm.nih.gov/pubmed/2365636; for the Readiness for Interprofessional Learning Scale (RIPLS), see www.ncbi.nlm. nih.gov/pubmed/10211258; and for TeamSTEPPS, see http://teamstepps.ahrq.gov/abouttoolsmaterials.htm.

Column 4: Competencies cross-referenced by competency code to the IPEC document referenced for Column 1.

Note: Suggested competencies in Column 2 are complementary to CODA Standards 1-9 and 2-19 (www.ada.org/sections/educationAndCareers/docs/pde_ssg_2013.doc):

Standard 1: Institutional Effectiveness

1-9 The dental school must show evidence of interaction with other components of the higher education, health care education, and/or health care delivery systems.

Standard 2: Educational Program

Practice Management and Health Care Systems

2-19 Graduates must be competent in communicating and collaborating with other members of the health care team to facilitate the provision of health care.

Team STEPPS=a training model designed to produce high-performing teams RIPLS=Readiness for Interprofessional Learning Scale 
Table 2. Respondents' reports of other health professions programs on their campus and collaborations with other programs (on or off campus), by number and percentage of responding dental schools $(\mathbf{N}=62)$

Other Health Professions Program

Other Program on Campus

Collaborate with Other Program

\begin{tabular}{lrr}
\hline Medical school & $51(82 \%)$ & $39(63 \%)$ \\
Nursing school & $51(82 \%)$ & $29(47 \%)$ \\
Pharmacy school & $40(65 \%)$ & $22(36 \%)$ \\
Physical therapy program & $40(65 \%)$ & $21(34 \%)$ \\
Psychology department & $40(65 \%)$ & $9(15 \%)$ \\
Social work program & $34(55 \%)$ & $18(29 \%)$ \\
Dental hygiene program & $31(50 \%)$ & $36(58 \%)$ \\
Other & $21(34 \%)$ & $20(32 \%)$ \\
Other allied oral health program & $9(15 \%)$ & $5(8 \%)$ \\
Dental assisting program & $6(10 \%)$ & $11(18 \%)$ \\
Dental therapy program & $1(2 \%)$ & $1(2 \%)$
\end{tabular}

Table 3. Types of joint activities and numbers of schools involved in IPE reported in survey $(\mathrm{N}=62)$

\begin{tabular}{|c|c|c|c|}
\hline Activity & Involved & $\begin{array}{l}\text { Most Frequently } \\
\text { Named Program }\end{array}$ & $\begin{array}{c}\text { Number of Schools } \\
\text { Collaborating with } \\
>1 \text { Program }\end{array}$ \\
\hline Joint volunteer activities & $41(66 \%)$ & Medicine: 19 & 5 \\
\hline Clinical activities & $37(60 \%)$ & $\begin{array}{l}\text { Dental Hygiene: } 11 \\
\text { Medicine: } 10\end{array}$ & 3 \\
\hline Service-learning projects & $32(52 \%)$ & Medicine: 10 & 4 \\
\hline Basic science courses & $20(32 \%)$ & Medicine: 6 & 1 \\
\hline Communication training & $19(31 \%)$ & Medicine: 5 & 8 \\
\hline Standardized patient programs & $14(23 \%)$ & Medicine: 6 & 4 \\
\hline Medical emergency or patient safety interactions & $13(21 \%)$ & Medicine: 5 & 2 \\
\hline Other activities & $13(21 \%)$ & Medicine: 7 & 0 \\
\hline Ethics classes & $9(15 \%)$ & Medicine: 3 & 5 \\
\hline Review of evidence-based practice activities & $7(11 \%)$ & Medicine: 3 & 1 \\
\hline Evaluation of health systems across and delivery of care & $6(10 \%)$ & Medicine: 4 & 1 \\
\hline
\end{tabular}

IPE with medical anesthesia and other medical specialties; community-based educational experiences in school-based settings, rural rotations, geriatric centers, or pediatric centers; and activities related to pain control, infection control, and CPR.

When asked which challenges related to IPE their dental schools had encountered in the past, the academic deans' answers fell primarily into three categories. The first category focused on organizational issues such as scheduling $(\mathrm{N}=27)$, finding a location, and not having enough time in the curriculum. The second category included challenges related to the persons involved in these activities, such as a lack of leadership support, not having trained faculty or faculty willing to be engaged, and a lack of support from students. The final category described cultural/ philosophical issues such as intra- and interprofessional resistance to this type of education. Similar responses were given to the question asking about challenges the schools encounter for IPE now and for the future.

\section{New IPE-Related CODA Standards}

The new CODA standards that will be implemented on July 1, 2013, include two standards related to IPE/team-based education. The survey respondents were asked to share how their school is currently demonstrating compliance with these standards or is preparing for compliance.

CODA Standard 1-9 states that "the dental school must show evidence of interaction with other components of the higher education, health care education, and/or health care delivery systems." The survey responses concerning current compliance with this standard focused on interactions in classroom settings, in clinical settings in the dental school, or 
in the community and on voluntary interactions during international trips or volunteer service activities. However, the interpretation of the phrase "interaction with other components" ranged widely and included having instructors from other disciplines teach the dental students or students' observing providers from other disciplines in clinics while on rotation. Some schools answered that they currently did not meet this standard. However, a strong effort was reported by many schools concerning their preparations for compliance with Standard 1-9 in classroom and clinical settings.

When asked how the schools currently assess or will assess their progress or outcomes in regard to Standard 1-9, the first group of responses focused on such quantitative data as the number of students participating, number of contact hours, or disciplines involved and such qualitative data as student course evaluations and surveys from students and alumni. Ways to assess outcomes of classroom-based educational experiences included group project presentations and performance on OSCEs and the National Board Dental Examination. Ways to assess outcomes of clinical rotations included having students write reflective journals, debriefing students after the rotations, using student presentations, and having staff or patients in the community clinics evaluate the students. Less frequently named ways were problem-based learning outcomes, focus groups, and portfolios. One school reported using two pre- and post-experience assessment tools: the Readiness for Interprofessional Learning Scales (RIPLS) and the Interdisciplinary Education Perception Scale. Online assignments such as contributing to a blog and assignments in wiki format were mentioned by one school each. Several schools stated that they were not in compliance with this standard at this time.

The second CODA standard related to IPE activities is Standard 2-19. This standard states that "Graduates must be competent in communicating and collaborating with other members of the health care team to facilitate the provision of health care." When asked how their schools currently demonstrate compliance with this standard, some respondents simply stated that their school currently does not comply with it. Schools that provided descriptions listed specific didactic educational experiences such as working with standardized/simulated patients or having specific courses that address these issues. Most respondents described clinical interprofessional experiences between students from different health professions, especially from dental hygiene, medicine, nursing, social work, and nutrition. Some of these descriptions of clinical activities, however, referred to the interactions between dental students and faculty members/clinicians from other health professions in clinical settings such as medical consultations and did not include interactions between students from different disciplines. Writing consultations and referrals within the clinical setting and written and verbal communication with outside health care providers were also named by respondents as IPE activities related to Standard 2-19. In addition, volunteer and outreach activities were reported as opportunities for activities related to this standard.

When asked how the schools prepare for compliance with Standard 2-19, some respondents described their schools' efforts to establish relationships with other health professions programs on their campus in order to either develop joint courses or engage the students in joint clinical activities. Examples of such courses are the plans of one school for a multidisciplinary course on communication and team approach and another school's course on a multidisciplinary approach to patient cases. Clinical efforts that were reported included placing dental clinics in multidisciplinary settings and creating student rotations to other professions' clinics on and off campus.

The responses concerning how schools will assess their progress or outcomes in regard to Standard 2-19 were similar to those concerning Standard 1-9. The methods ranged from collecting objective data such as determining how many students interact for how many hours with members of how many different health professions programs to subjective data collected from interviews, course evaluations, surveys throughout the program, and end-of-program exit surveys. Graded exercises, OSCEs, reflective journals, evaluations of clinical performance and behavior, field projects, portfolio preparation, and focus groups were listed as well. One school mentioned pre- and post-course assessments with the RIPLS and the Interdisciplinary Education Perception Scale.

When asked to indicate on a scale from 1 (not at all important) to 4 (extremely important) how important the implementation of IPE was among their top five priorities as an academic dean, eight respondents indicated not important at all, and twenty-four respondents rated it as extremely important; twelve rated it with a 2 and eighteen with a 3 . When asked to explain their response choice, those who ranked IPE more highly referred to the importance of seeing dental care as part of the complete health care system. Those who ranked it low tended to either point 
to organizational issues such as budgetary concerns or to marginalize IPE as one of many concerns and think it not as important as others.

\section{Competencies Related to IPE}

One section of the survey asked the respondents to rate several competencies related to IPE on a scale from 1 (not at all important) to 4 (extremely important). Not all the respondents thought these competencies were important (Table 4). However, the responses ranged from 2 to 4 , reflecting a wide range of perspectives.

\section{Dental Schools' Best IPE Practices}

The dental schools were asked to provide information about their own best practices related to IPE. From the responses received, the study group selected six schools that were willing to share their practices as case studies. Study group members drafted the case studies, and each school reviewed and approved its case.

\section{Western University of Health Sciences, College of Dental Medicine}

Western University of Health Sciences was founded in 1977 as a graduate health science university. It is located thirty miles east of Los Angeles,
CA, and consists of nine colleges-Colleges of Osteopathic Medicine, Allied Health, Pharmacy, Biomedical Sciences, Graduate Nursing, Veterinary Medicine, Optometry, Dental Medicine, and Podiatric Medicine - as well as three research centers. Western University embraces IPE as a central underlying principle of all its activities and states that its IPE program mission is "to produce humanistic health care professionals who practice collaborative patient-centered care." The program outcomes are described as follows: "The Western University graduate will a) demonstrate an understanding of other health professions and $b$ ) provide and promote a team approach to health care."

For the purpose of planning and developing IPE activities, a clear organizational structure was developed. This structure consists of an IPE Oversight Committee, eight IPE Faculty Work Stream Groups, Faculty Calibration Sessions, an IPE Design Team, an Implementation Committee, and the Dean's Council. The university has a Department of Interprofessional Education that is connected to the other colleges through college faculty liaisons. Case-based education in small groups is used as the educational methodology to achieve the first-year IPE objectives. In addition, students in the various colleges interact through online IPE wiki projects and in the Standardized Patient Program, the Patient Care Center, and off-campus rotations.

College of Dental Medicine students participate in the campus-wide IPE courses in their first and second years. In the first year, the IPE 5000 course, Patient-Centered Cases: An Interprofessional Approach

Table 4. Survey responses on the importance of IPE competencies, by number of respondents and mean (SD)

\begin{tabular}{|c|c|c|c|c|c|}
\hline Statement & 1 & 2 & 3 & 4 & $\begin{array}{l}\text { Mean } \\
(\mathrm{SD})\end{array}$ \\
\hline $\begin{array}{l}\text { Graduates must be competent to work with individuals of other } \\
\text { professions to maintain a climate of mutual respect and shared values. }\end{array}$ & 0 & 3 & 21 & 31 & $\begin{array}{c}3.51 \\
(0.605)\end{array}$ \\
\hline $\begin{array}{l}\text { Graduates must be competent to use the knowledge of their own roles } \\
\text { and those of other professions to appropriately assess and address the } \\
\text { health care needs of the patients and populations served. }\end{array}$ & 0 & 4 & 20 & 31 & $\begin{array}{c}3.49 \\
(0.635)\end{array}$ \\
\hline $\begin{array}{l}\text { Graduates must be competent to communicate with patients, families, } \\
\text { communities, and other health professionals in a responsive and } \\
\text { responsible manner that supports a team approach to the maintenance } \\
\text { of health and treatment of disease. }\end{array}$ & 0 & 2 & 17 & 35 & $\begin{array}{l}3.61 \\
(0.564)\end{array}$ \\
\hline $\begin{array}{l}\text { Graduates must be competent in applying relationship-building values } \\
\text { and the principles of team dynamics to perform effectively in different }\end{array}$ & 0 & 10 & 19 & 26 & $\begin{array}{c}3.29 \\
(0.762)\end{array}$ \\
\hline
\end{tabular}

team roles to plan and deliver patient/population-centered care that is safe, timely, efficient, effective, and equitable.

Note: Answer scale ranged from $1=$ not at all important to $4=$ extremely important.

$\mathrm{SD}=$ standard deviation. 
I, takes place in the fall term, followed by IPE course 5100, Patient-Centered Cases: An Interprofessional Approach II, in the winter term. In the second year, the course Interprofessional Education 6000 takes place in the fall term, followed by Interprofessional Education 6100 in the winter term. The first-year courses started being held in 2009-10, and the second year courses began in 2010-11. The courses are administered by the university's IPE department, but all nine colleges helped to create the courses through college liaisons appointed to each. These courses are mandatory for graduation. However, some TeamOSCE events with standardized patients are being piloted and are currently electives. The expectation is to have all second-year students rotate through the Team-OSCEs, which are graded by volunteer faculty members. All nine health professions are represented among the faculty members for each course. Students from all nine colleges interact with each other in the first- and second-year courses.

Extensive outcome evaluation data have been collected in post-course focus groups with faculty members and students, pre- and post-course surveys, and a standardized scale (the RIPLS). The initial results concerning the first-year courses showed that the students preferred case closure in a small-group format over large IPE grand rounds. Students wanted more foundational knowledge on communication, scope of practice, and why IPE is important. After two cases, the students were not as challenged with the content and wanted the cases to build in complexity. Concerning the outcomes related to faculty behavior, the data showed that the grading was sometimes subjective and varied among the facilitators. Not all faculty members were on board. Based on these findings, changes were made, and the evaluation of these courses is ongoing.

In addition, a formal Phase III clinical component of IPE is in development and will be launched in the 2012-13 academic year. These clinical IPE activities will take place in the Patient Care Center Interprofessional Unit and off-campus rotations. Through these activities, students will work on IPE portfolios.

Other IPE opportunities exist for students in service-learning activities, the basic science and human systems courses, interprofessional health fairs, and interprofessional clubs. Currently, the students are also involved in interprofessional clinical experiences. They participate in asynchronized, community care-focused, team-based clinical skills activities, have interprofessional clinic rotations in the on-campus Patient Care Center and off-campus interprofessional rotations at a rehabilitation hospital and geriatric and HIV clinics. For more information on Western University's IPE approach and programs, visit www.westernu.edu/interprofessional-about.

\section{Medical University of South Carolina, James B. Edwards College of Dental Medicine}

After pilot-testing in 2009, Transforming Health Care for the Future, an IPE course at the Medical University of South Carolina, was implemented in 2010-11 as a mandatory course for all first-year dental students in the James B. Edwards College of Dental Medicine. The university-wide course includes students in dentistry, medicine, nursing, pharmacy, and the College of Health Professions. The course helps provide foundational knowledge for beginning health professions students to help them understand the complexities of the health care system and how interprofessional collaboration can improve the system. The course was created by faculty members from ten disciplines and has two codirectors.

The course is arranged around an introductory session on interprofessional collaboration and four modules: the health care system and calls for improvement; negotiation across cultures; social determinants and health disparities; and evidence-based decision making in practice and research. There are twelve students in each section, and students respond online to questions posed in each model. Students are expected to prepare and share a response of 250 to 300 words to each question. They prepare for class discussions by reading all of the postings of their classmates.

In addition to the preparation and classroom discussion around each of the four modules, interprofessional teams of four or five students are required to analyze and provide recommendations around a fictitious sentinel event (an unexpected occurrence involving death or serious physical or psychological injury). Students conduct a root cause analysis that guides their understanding of the initial and subsequent problems presented in the case. These groups meet on their own time, and each team makes a PowerPoint presentation on the event describing the interprofessional problem-solving process they used in getting to the root cause and subsequent recommendations. A detailed seventeen-page syllabus provides information to the students. The course is graded on a pass/fail basis. Exit data on the course 
will be collected from the first graduating class involved after two years. However, the dental students as well as the other health professions students seem to be very satisfied with the course based on initial student evaluations.

The course is a component of MUSC's Creating Collaborative Care (C3) program, a quality enhancement plan that focuses on IPE. Other $\mathrm{C} 3$ activities include IPE fellowships for students and faculty members, Interprofessional Day, interprofessional service-learning projects, health care simulation exercises, and interprofessional electives. Interprofessional Day is a particularly special day on campus as first- and second-year students from six colleges gather to discuss interprofessional case studies and scenarios. While there are no currently planned interprofessional clinical experiences for dental students this academic year due to scheduling issues, the university and College of Dental Medicine continue to seek opportunities for interprofessional clinical experiences. Additionally, dental students participate in various volunteer experiences at free clinics and on medical mission trips.

\section{University of Colorado, School of Dental Medicine}

The University of Colorado Health Science Center fully implemented mandatory IPE coursework in the 2010-11 year. Dentistry, medicine, physical therapy, physicians assistant, pharmacy, nursing, and public health are the disciplines involved in the IPE. The medical school administers the program, which has four components: Fundamentals of Collaborative Care, modeled on a component developed at Thomas Jefferson University in Philadelphia; Ethics; the Clinical Transformation; and the Interprofessional Clinical Rotations Programs. Grants of approximately $\$ 2.0$ million are helping the medical campus plan and implement the IPE experiences for students.

The Fundamentals of Collaborative Care program recruits individuals with chronic physical or mental illness and/or disability as instructors to meet every six weeks with interprofessional teams of four to six students in the first year of the curriculum. Four two-hour sessions are spread over a six-month timeline. Roles and responsibilities of the various health professions are built into the sessions, along with teamwork and communication skill development. Students with their health mentors assess medical history, review home safety, and gain insight into the health care system, including access and complete medicine reconciliation. Dental and medical students in years 1 through 3 and public health and nursing students in years 1 and 2 interact in these groups. Initial outcome data show a very positive learning experience, with some indications that dental students find that certain scenarios are not relevant to dental practice and desire more time in simulations. Timing within the curriculum and course time commitment are the largest issues for all students.

The Fundamentals of Collaborative Care program is aligned with a fifteen-year-old interprofessional course in bioethics that stresses communication and decision making. These are followed up in a Clinical Transformations program using TeamSTEPPS as a training model. TeamSTEPPS, developed originally by the Department of Defense Patient Safety Program with the Agency for Healthcare Research and Quality (AHRQ), is designed to train high-performing teams. It has been found to reduce medical errors and to improve safety. Colorado has adapted this program as the knowledge base and transition for IPE into the clinical arena. Interprofessional student groups follow up TeamSTEPPS with cases involving standardized patients or mannequins. Video monitoring is used to provide feedback to the students. The final phase of Colorado's program entails Community Health Rotations. This phase is now in the planning stage. The website provides more information: www.ucdenver.edu/academics/degrees/ health/REACH/About/Pages/default.aspx.

\section{Columbia University, College of Dental Medicine}

A new elective course, Interprofessional Teamwork, has been developed at Columbia University over the past one-and-a-half-year planning period by a group consisting of two faculty representatives of each of the four schools at Columbia University Medical Center: dentistry, medicine, nursing, and public health. The course started in the spring of 2012 (January 18, 2012, to May 2, 2012). It is jointly administered by the four schools, and faculty members from all four schools participate in the teaching.

At this time, the course is elective, and only four students from each school (two second-year and two third-year students from dentistry, and four first-year students each from medicine, nursing, and public health) were admitted after being selected on the basis of a competitive essay. For this course, the students are grouped into four "tetrads," each of which has one student from each school. The tetrads 
are given special assignments during each session and for midterm and finals. One of the strong requests from the students is for more tetrad time. They have come together as teams and enjoy working on the assignments together. One finding is that the faculty do not recognize in which school the students are enrolled (except of course their own students). It is hoped that one of the follow-up events of this elective course will be a day-long "mutual respect and teamwork awareness" program for the incoming students of all four schools in the fall semester of 2012. Students who completed the spring 2012 course will be asked to teach this program along with the interdisciplinary faculty.

Outcome data are limited at this time. Each session is evaluated in writing by all students. The students describe what worked and what they would like to change, add, or delete. The comments are summarized and distributed among the entire group, and when possible, requested adjustments are made prior to the next session. At the end of the course in May 2012, an in-depth evaluation was done, based in part on student responses and their performance in the final team project (results not yet analyzed). However, the students' satisfaction at the midpoint of the course was high, both in the written evaluations for each session and by evidence that they have been spreading the word among their colleagues who do not attend the course.

For one assignment, tetrads were asked to generate a general code for health professionals. The statements in their code were as follows:

- We will work for the benefit of the patient, whether an individual, group, or community.

- We will work to practice in uprightness and honor and ensure that people have the chance to live full and productive lives, free from avoidable disease and disability and supported in their pursuit of physical, mental, and social well-being.

- We will serve with truth and skillful knowledge in one hand and compassion and service in the other.

Expected changes for the future of this course include expanded time for the small groups (tetrads) to work together. One of the goals of this course is to develop a group spirit with interprofessional respect for all group members. In addition, training sessions for additional pairs of faculty members from each school will be offered to allow increasing the number of students who can participate in the course.

This course impacts other interprofessional activities in which these students are engaged. For example, the students have developed IPE contacts, and some are working together in outreach clinics in the neighborhood (e.g., CoSMO: Columbia Medical Student Outreach with medical and dental students). In addition, the schools of dentistry, medicine, and public health all have expanding global health programs and global service missions. While these programs have been profession-specific in the past, a growing number of them are now developing IPE activities (e.g., La Romano in the Dominican Republic). At present, 75 percent of the dental students participate in at least one global health service mission while at Columbia.

At this time, interprofessional experiences are not integrated into other courses, and there are no other courses specifically for IPE. However, the schools are working together to this end. The dental school is currently evaluating the needs for social workers in the dental school clinics. The hope is that the School of Social Work will establish a field unit in the dental clinic, and an IPE program will be developed for dental and social work students. The dental school also has invited nursing students to participate in its Primary Medicine Grand Rounds course, during which the third-year dental students present some of their own medically complex patients.

\section{University of Minnesota, School of Dentistry}

The University of Minnesota Academic Health Center has health professions programs in dentistry, medicine, pharmacy, nursing, veterinary medicine, public health, and allied health. In 2010, the Academic Health Center initiated a program called "1Health." 1Health is comprised of three phases that correspond to students' progression through their respective programs. Following the AIM framework, the first phase is Awareness, the second phase is Immersion, and the third is Mastery. The first phase is mandatory for all beginning health professions students (except those in public health) and is completely implemented. The second phase is partially implemented, and the third phase (representing the clinical phase of health professions programs) is undergoing highpriority, extensive planning. The goals of 1 Health are to consistently and longitudinally reinforce the principles of interprofessional collaborative practice during the educational programs of health professions students, helping them learn to work in teams and to develop mutual respect and understanding among the various health professionals in order to deliver optimal patient care. 
Phase 1 of 1 Health is comprised of a mandatory course entitled Foundations of Interprofessional Communication and Collaboration (FIPCC). All of the clinical health professions schools reserve five half-days in the fall of their first year that can only be used for this course. Close to 900 Academic Health Center students are required to take this course in their first semester of their programs. The course is given in small-group settings with each group consisting of twelve students from multiple professions. Each group meets face-to-face for ten hours of discussion and also works together online to share thoughts and opinions. Since each group has a facilitator and over seventy groups are meeting at the same time, the need for facilitators presented a major challenge for schools at the onset. Schools forced to be innovative in finding facilitators resulted in the schools' asking community health professionals and leaders to help. The response was phenomenal, and the support from the community represents a major strength of Phase 1.

The FIPCC course has five objectives for its students: to help them 1) develop an awareness of the diversity of expertise in interprofessional teams, 2) acquire exposure to the positive and negative experiences of interactions and communication with patients, families, health professionals, and communities, 3) establish basic concepts of effective teamwork, 4) explore the emerging concept of interprofessional ethics and professionalism, and 5) gain experience in decision making in the interprofessional environment. The course is evaluated in several ways. Students complete the Readiness for Interprofessional Learning Scale and the Interdisciplinary Education Perception Scale as part of the course. These surveys will be repeated in later phases of 1Health. Facilitators and students both complete course evaluations at the end of the course, leading to many changes based on this feedback. The evaluations have improved dramatically, and for the 2011 version it appears that students think very highly of this course. Students are evaluated on their attendance and participation in discussions. The course is graded $\mathrm{P} / \mathrm{F}$, and students who fail must complete remediation. Students will automatically fail if more than one class is missed; however, it is noteworthy that, of the almost 900 students, not one missed more than one class session in 2011, and some groups opted for an additional session.

For Phase II of 1Health, each school will identify available interprofessional courses that would be of value to their students. The students will then select which one or two courses are of interest to them or fit best with their long-term career goals. The Academic Health Center has a grant program to help fund more interprofessional courses for Phase II. Phase III is being developed in cooperation with community employers of the health professions graduates. The dental school has been a major player in the development of 1Health and in the FIPCC course.

\section{University of Florida, College of Dentistry}

At the University of Florida (UF) College of Dentistry, IPE has long been a priority in the curriculum. Development of these courses began in 1997 , and presently IPE experiences are provided primarily within the first year of instruction. Recently, the university's senior vice president for health affairs identified expansion of this initiative as a top priority. With the support of the university administration and spearheaded by the UF College of Medicine, a multidisciplinary expansion of existing experiences is under way.

Currently, the IPE experience at the UF College of Dentistry is housed primarily within the first-year course DEN 5010 and secondarily within service-learning and intra- and extramural rotation experiences spanning all four years. All of these experiences are mandatory. The two major components of the first-year IPE curriculum are Interprofessional Family Health (IFH), a course administered by the medical school since 1999, and the AHEC Tobacco Training and Cessation Program (ATTAC-IT), which is managed by UF AHEC and faculty members throughout the UF Health Science Center. Total clock hours for these two segments are twenty-four for IFH and twelve for ATTAC-IT.

The IFH course is designed to initiate an interdisciplinary learning practicum for health professions, pharmacy, nursing, dental, and medical students. The central theme of the course is learning as a team about the impact of resources and the environment on health status. Students learn to conceptualize family health beliefs and behavior from a biopsychosocial framework, and they learn to assess family health care needs and health care access through a multidisciplinary lens. These experiences are carried out via interdisciplinary team home health visits and facultyfacilitated small-group discussions. The number of participants has increased gradually over the years since the inception of the course. In the 2011-12 school year, 617 students from dentistry, medicine, 
nursing, pharmacy, physical therapy, nutrition, and clinical psychology participated. Using course evaluations, student presentations, and reflection papers, the course is continually modified and improved. For example, an increased emphasis on the fundamentals of teamwork was added this year in response to the previous year's evaluations. Dental students overall consistently rank their participation in the IFH course as very positive, ranking highest numerically of all of the professions with an overall score of 3.8/5.0 in the course evaluation. This course is in the process of expansion, and a second year of IPE activities within the IFH course will be initiated in fall 2012.

The ATTAC-IT program is another critical component of the first-year IPE curriculum. It is a highly condensed, two-day experience that involves 820 interdisciplinary students from nine health professions schools, including public health. Students are introduced to a curriculum designed to educate middle school students about the dangers of tobacco use. They first meet in interdisciplinary teams to determine how the curriculum will be delivered, and on the second day, they present the information as team teachers to a middle school class. The dental students have averaged 4.1/5.0 on the evaluation scale and shared numerous positive insights in the required reflection paper, thus seeming to evaluate the course very favorably.

The third component of the first-year IPE experiences housed within DEN 5010 is required service-learning. Ten hours of service-learning experiences are required each academic year, for a total of forty clock hours over four years. Students are urged to fulfill these required hours in interdisciplinary settings, and many opportunities to participate in interdisciplinary opportunities are offered to the students. These include participation in the UF College of Medicine's Equal Access Clinic and mobile health van, numerous health fairs, and school health outreach. These experiences span all four years of the dental curriculum and are evaluated yearly via standardized evaluations and prior to graduation with a reflection paper, both of which have been very positive overall.

The secondary IPE experiences occur primarily in years 2-4 via intra- and extramural rotations. These are less formal IPE experiences than those in the first year, but they offer clinical enhancement of the skills gained previously. Intramurally, students participate in mandatory rotations in oral surgery by covering hospital calls (thirty-two clock hours); they also participate in the head and neck tumor board as part of their oral oncology rotation (twelve clock hours). Extramurally, during their senior year, students spend six weeks in community safety net settings (216 clock hours), all of which are required to take place in interdisciplinary facilities. The students may participate in any clinical care and outreach in which the facility engages while they are assigned there, which has the potential to increase their involvement in IPE experiences.

Finally, in an effort to enhance students' exposure to IPE prior to matriculation into the D.M.D. program, the school recently requested funding for a program that will allow accepted students to spend six weeks in safety net settings throughout the state with other pre-health professions students. In those settings, the students will engage in various aspects of those facilities' work, including helping patients to develop health improvement plans.

\section{Discussion}

The survey results suggest that the academic deans of dental schools in the United States and Canada believe that the subject of IPE is an important one to address. The 86 percent return rate can be interpreted as an indication that most schools' academic deans are interested in learning how the IPE movement is progressing. Opportunities for dental schools to include IPE experiences for their students seem abundant. We found a wide array of programs featuring IPE collaborations, ranging from those with medical and nursing schools to others with pharmacy and social work programs. Distinctive collaborations are also occurring as some dental schools reported conducting educational activities jointly with such fields as optometry, public health, podiatry, and journalism. The potential for dental students to interact with students in a wide range of fields pertinent to health and health care is widespread.

To explore the nature of current collaborations, the survey asked how frequently dental schools engaged in joint activities with other schools or programs. In the responses, joint volunteer activities led the list of joint activities. While these joint volunteer activities were most often with medical schools, some consisted of activities with up to five other schools or programs. Joint clinical activities, learning projects, basic science courses, and communication training were reported as ongoing activities for approximately one-third of the schools; the medical school was again most often named as the 
collaborating partner. However, in some instances, these efforts involve up to eight separate programs. These joint activities seem consistent with part of the definition of IPE since they involve occasions in which students from two or more professions learn together. Whether these joint activities are designed to meet IPE's ultimate objective of cultivating collaborative practice to improve the quality of patient care at the individual and population levels cannot be determined due to a lack of outcome assessments. However, it should be noted that having students from different disciplines merely attend the same lecture courses does not satisfy the definition of IPE.

There was wide agreement among the respondents concerning the importance of the four competencies named in the survey (mutual respect and shared values; understanding of professional roles to address patient and population needs; communication to support a team approach; and team dynamics to deliver care). However, the respondents' answers suggest that the challenges related to planning and developing coursework to achieve these competencies are as difficult as reported six years ago. ${ }^{10}$ Including activities for students from separate health professions in already crowded curricula and course schedules, lack of leadership support in health sciences centers, lack of a willing and trained faculty, and even a lack of support from students top the list of major challenges the survey respondents identified concerning further IPE program development.

The study group began from the point of view that IPE is a way to improve patient care, given the complexity of managing chronic care and the need to involve multiple caregivers to promote health and prevent disease. To be part of the primary care system in managing chronic health conditions (such as diabetes) that involve the oral cavity, to prevent early childhood caries, and to become more involved with the public health system to ensure access to care for underserved patients and populations require a team approach. To overcome existing challenges will require leadership from all levels in order to prevent the IPE movement in dental education, and most likely the other professions, from becoming little more than a rationalization of current silo-style educational practices to satisfy accrediting requirements. Some respondents in our survey indicated that their schools currently did not meet the new CODA standards (Standards 1-9 and 2-19) regarding team-based education. Most likely, those schools are viewing these standards in regard to the spirit of the definition of IPE stated above. Some respondents who indicated their schools did meet the standards reported activities that probably would not meet the definition of IPE. These CODA standards are new and do not go into effect until the 2013 accrediting cycle. How the accrediting teams will interpret these standards and how teams will evaluate schools' responses to the standards will become an important determinant of whether IPE becomes a firmly established reality in dental education.

Within dentistry, opportunities for intraprofessional collaboration between predoctoral dental programs and dental hygiene programs were reported to be available for at least half of the responding schools. However, there were few opportunities to collaborate with dental assisting programs (only 10 percent of the respondents reported such collaborations). Unfortunately, none of the schools reported any best practices for collaborations between dental students and dental hygiene, dental assisting, or other students in the allied dental health workforce. While examples of intraprofessional best practices may exist in dental schools, the respondents may not have reported them because the nature of the survey may have appeared to be directed only at interprofessional programs. Intraprofessional education programs should have similar goals to those for interprofessional educational programs, and it could be theorized that recognition of benefits for one complements the other. As dental education continues to explore its role in IPE (and as a follow-up to this report), the state of intraprofessional education needs attention. Cost-effective, efficient quality oral health care depends upon teamwork in dental practice. It may be timely to focus renewed attention in dental education, especially in the clinical arena, on teamwork within the dental workforce.

The six case studies show that while there are a variety of approaches to the design and management of IPE content in these dental schools, there are three common traits: 1) using a small-group format to allow interactions among students from different professions; 2) including active learning assignments/projects; and 3) offering foundation knowledge coursework for beginning health professions students. The scope of approaches is wide: ranging from offering a single elective course (Columbia University) to embracing IPE as a central underlying principle of all the health professions schools on campus (Western University of Health Sciences).

The design and management of actual courses at these dental schools illustrate the creativity and imagination of the faculty members involved. The 
subject matter and modes of instruction vary from school to school, most likely based on the faculty members' perspectives and backgrounds. For example, courses at the University of Florida are designed around the themes of family health and tobacco cessation, using a home visit setting, while modules at the Medical University of South Carolina use online discussions and root cause analysis projects.

The dental schools also differ in the participants they involve in educational activities in addition to students and faculty members from various health profession units. For example, the University of Colorado engages people with chronic illness as health mentors to interact with the students. This dental school, as well as that at Western University of Health Sciences, utilizes standardized patients. The University of Minnesota Academic Health Center engages community health professional facilitators, and on the Columbia University Medical Center campus, student peer instructors will be involved in programs that aim at increasing mutual respect and raising team awareness.

The administrative structure also differs widely from dental school to dental school as they work within their university and/or health science center structures. Western University of Health Sciences even has a university-wide IPE department. The diversity of topics addressed, the methodology used, and the organization and management of the coursework reflect the resources available at local sites as well as the mission of the particular organizations. However, all IPE programs share a common purpose: to engage health professions students in learning together to develop a sound understanding of the value of a team approach to patient care.

Most of the coursework reported in our study was introduced in the 2009-11 time period. According to these respondents, one school launched its courses as pilots (Medical University of South Carolina), another school offers only an elective course (Columbia University), and the rest require this coursework for their students. These findings suggest that we are truly in the first phases of planning and developing IPE in dental education. While most of the schools have volunteer efforts for students to use their foundation knowledge in clinical settings, Western University of Health Sciences has developed interprofessional clinic rotations in its on-campus patient care center and off-campus interprofessional rotations at a rehabilitation hospital and at geriatric and HIV clinics. Ideally, as the IPE movement matures, these centers and others around the country will extend IPE efforts from offering foundational knowledge coursework to integrating this approach into clinical settings.

Given the diversity of approaches to IPE in these six settings, it would seem appropriate for administrators of health science campuses to provide opportunities for faculty members to gain an understanding of the best practices developed on other campuses and the ways challenges can be overcome. National conferences and workshops can be important ways to provide training.

The survey used in our study was an early survey in the development of IPE programs in dentistry. One of the limitations of the survey is that it did not collect data from the students directly on their perceptions of IPE or whether students on most campuses are aware of the need for IPE in dentistry. Future surveys should seek student opinions. The Curriculum Survey conducted by ADEA and the American Dental Association should be reviewed to determine whether there are questions pertaining to IPE and whether additional information on IPE should be collected on that survey.

\section{Study Group Recommendations}

At the conclusion of its work, the study group agreed on a set of recommendations for dental schools regarding IPE:

1. As schools consider IPE with students from the various health professions, it appears that attention is also needed to develop or strengthen intraprofessional education among dental students, dental hygiene students, and the rest of the oral health team, including newly emerging members of the oral health workforce such as dental therapists. Little attention has been given in recent decades to interactions among these students, especially in the patient care arena, to help them learn from each other to improve the quality and efficiency of care.

2. During the planning process for IPE activities, it is critical to engage and receive the support of the leadership of the health science center and to include all of the health care disciplines for such efforts to be successful. In academic medical centers, it is especially important to make sure there is strong buy-in from the medical school.

3. When schools are planning IPE learning programs, it is of paramount importance to keep in 
the forefront that the focus of IPE is to improve the quality of patient care through multidisciplinary teamwork. Active coursework should be planned, and teams should include fields beyond medicine and dentistry. Students and faculty members from social work, nursing, physical therapy, public health, and other disciplines should interact around patient problems and the health care system.

4. Evaluation of IPE efforts should be built into the planning and implementation of coursework. Assessing outcomes in relation to IPE's ultimate objective-improved patient care due to a team approach - should be the ultimate goal of the evaluation process.

5. As schools think about how to emphasize teamwork, it is worthwhile for faculty members and academic administrators to consult with and gain the perspectives of employers of health providers. Most provider systems, whether in hospitals, community-based clinics, or private practices, depend on teamwork among various levels of the health care team to ensure that patients have a high-quality outcome and a positive experience. Additionally, these individuals' perspectives will expand current and define future employment/ practice models.

6. To plan and implement successful IPE programs will require trained faculty. Most current faculty members are accustomed to working within the silo approach to care and the education of students. Dental schools will need to invest in both intra- and interprofessional faculty training to develop a cadre of faculty members prepared to develop IPE coursework.

\section{Conclusions}

On the basis of our research, the ADEA Team Study Group concludes that the importance of IPE in dental education is widely recognized by the schools and that there is concurrence regarding the competencies necessary for graduates to become practitioners able to participate more fully in a team approach to interprofessional care. However, the responses to the survey show that there are major challenges to incorporating IPE into dental school curricula. There appears to be sufficient interest for dental schools to take on these challenges and plan and develop IPE, but leadership within the schools and the health science centers in addition to funding sources will be needed to provide the necessary resources for IPE to take hold throughout the United States and Canada. The best practices reported here from schools willing to share their experiences indicate that some health science centers are paving the way.

Future surveys and studies should focus on whether courses being offered actually meet the definition of IPE. In addition, the way schools develop team competencies for dentists and allied dental health professionals requires much greater attention because if those relationships are not robust within the dental professions, it is difficult to understand how dentistry can expand interprofessional relations with other disciplines. Some respondents who indicated their schools did meet the CODA standards reported activities that probably would not meet the definition for IPE. Such activities as having instructors from another discipline teach dental students or having students observe providers from other disciplines, for example, would not meet the definition of IPE. However, some of the planned activities such as multidisciplinary communication and patient care courses are on the right track.

Educating competent students who are fully prepared to maximize patient outcomes through interdisciplinary patient care is the ultimate goal of IPE and health sciences education. The findings and recommendations of this study group can help academic dental institutions in the United States and Canada discover pathways to the interdisciplinary education that will help the profession meet that goal.

\section{Acknowledgments}

We gratefully acknowledge the contributions of the following individuals who submitted the case studies: Elizabeth Andrews, College of Dental Medicine, Western University of Health Sciences; Lindsey Hamil, James B. Edwards College of Dental Medicine, Medical University of South Carolina; Brad Potter, School of Dental Medicine, University of Colorado; Letty Moss-Salentijn, College of Dental Medicine, Columbia University; Judith Buchanan, School of Dentistry, University of Minnesota; and Venita Sposetti and Gail Schneider Childs, College of Dentistry, University of Florida. We also extend special thanks to the reviewers of the report: Elizabeth Andrews, Interim Assistant Dean for Academic Affairs, College of Dental Medicine, Western University of Health Sciences; D. Gregory Chadwick, Interim Dean, School of Dental Medicine, East Carolina University; Carol Ann Murdoch-Kinch, Associate Dean, School of Dentistry, University of Michigan; Brad 
Potter, Associate Dean, School of Dental Medicine, University of Colorado; Cecile Skinner, Associate Dean for Academic Affairs/Student Affairs, Howard University, College of Dentistry; and Lisa Tedesco, Vice Provost for Academic Affairs and Dean, Laney Graduate School, Emory University.

\section{REFERENCES}

1. Interprofessional Education Collaborative Expert Panel. Core competencies for interprofessional collaborative practice: report of an expert panel. Washington, DC: Interprofessional Education Collaborative, 2011. At: www.aacn.nche.edu/education-resources/ipecreport.pdf. Accessed: April 15, 2012.

2. Thistlethwaite J, Moran M, World Health Organization Study Group on Interprofessional Education and Collaborative Practice. Learning outcomes for interprofessional education (IPE): literature review and synthesis. J Interprof Care 2010;24:503-13.

3. Parsell G, Bligh J. Educational principles underpinning successful shared learning. Med Teach 1998;20:522-9.

4. Reeves S, Zwarenstein M, Goldman J, Barr H, Freeth D, Koppel I, Hammick M. The effectiveness of interprofessional education: key findings from a systematic review. J Interprof Care 2010;24(3):230-41.

5. Cameron A, Rennie S, DiProspero L, Langlois S, Wagner $\mathrm{S}$, Potvin $\mathrm{M}$, et al. An introduction to teamwork: findings from an evaluation of an interprofessional education experience for 1,000 first-year health science students. J Allied Health 2009;38:220-6.

6. Carpenter J. Interprofessional education for medical and nursing students: evaluation of a programme. Med Educ 1995;29:265-72.
7. Carpenter J. Doctors and nurses: stereotype and stereotype change in interprofessional education. J Interprof Care 1995;9:151-62.

8. Luecht RM, Madsen MK, Taugher MP, Petterson BJ. Assessing professional perceptions: design and validation of an interdisciplinary education perception scale. J Allied Health 1990;19:181-91.

9. Simmons T, Egan-Lee E, Wagner S, Esdaile M, Baker L, Reeves S. Assessment of interprofessional learning: the design of an interprofessional objective structured clinical examination (iOSCE) approach. J Interprof Care 2011;25:73-4.

10. Rafter M, Pesun I, Linfante J, Mina M, Wu C, Casada J. A preliminary survey of interprofessional education. J Dent Educ 2006;70(4):417-27.

11. Prakash P, Lawrence H, Harvey B, McIsaac W, Limeback H, Leake J. Early childhood caries and infant oral health: paediatricians' and family physicians' knowledge, practices, and training. Paediatr Child Health 2006;11(3):151-7.

12. Team-based competencies: building a shared foundation for education and clinical practice. Proceedings of a conference supported by the Josiah Macy Jr. Foundation, the ABIM Foundation, and the Robert Wood Johnson Foundation, February 16-17, 2011, Washington, DC. At: http://macyfoundation.org/publications/publication/ team-based-competencies-building-a-shared-foundationfor-education-and-clin. Accessed: April 15, 2012.

13. Institute of Medicine. Educating for the health team. Washington, DC: National Academy of Sciences, 1972.

14. Institute of Medicine. Crossing the quality chasm. Washington, DC: National Academy Press, 2001.

15. Institute of Medicine. Health professions education: a bridge to quality. Washington, DC: National Academy Press, 2003. 